\title{
EL IRREVOCABLE LAZO ENTRE MERCADO Y MODERNIDAD
}

\author{
Danilo Martuccelli \\ Université Paris Descartes
}

T al vez el principal mérito del libro de Carlos Peña sea el de ser un libro necesario. Lo es, al menos, desde la óptica que trataré de reseñar a continuación. La obra defiende, con pasión y con razón —las dos actitudes al unísono-, una tesis poco habitual en las ciencias sociales en América Latina: la indispensable función del mercado en el advenimiento de la modernidad y del individualismo. El solo hecho de enunciar esta tesis, y el autor lo sabe con creces, suscita inmediatamente las más enconadas reacciones en la región. En verdad, salvo en la cultura anglosajona, el elogio del mercado es una verdadera rareza. En América Latina es un escándalo. Lo es al punto de que, si los historiadores han mostrado, un poco por doquier, la función civilizatoria del mercado y de los mercaderes, esta tesis y esta mirada brillan por su relativa ausencia en la región.

El libro de Peña rehabilita, con talento, esta problemática y lo hace no a través de una nueva defensa - de índole política o económicadel mercado, sino a través de un análisis pormenorizado de la función $\mathrm{y}$ de los fundamentos del mercado en la modernidad. Aunque el libro

Danilo Martuccelli. Doctor en sociología por l'E.H.E.S.S. de París. Profesor de sociología en la Université Paris Descartes. Entre sus trabajos destacan Sociologías de la modernidad (1999), Gramáticas del individuo (2002), Forjado por la prueba (2006), Les sociétés et l'impossible (2014), Poderes sociales y jerarquias culturales (2015) y La condition sociale moderne (2017). Email: danilo.martuccelli@ parisdescartes.fr. 
tenga muchas aristas, ésta me parece ser la tesis principal, la más sólida y polémicamente desarrollada.

La obra está estructurada en tres grandes capítulos, cada uno de ellos articulado a través de interpretaciones, muchas veces altamente originales, de autores clásicos o contemporáneos (estos últimos, por lo general, precedidos por una interesante y poco frecuente descripción física de los mismos). Los capítulos 1 y 3 se abocan de manera explícita al desarrollo de la tesis del lazo entre el mercado y la modernidad, mientras que el capítulo 2 se detiene en la discusión, desde una mirada contemporánea, de problemas o críticas habitualmente dirigidas al mercado. La estructura del libro revela, con transparencia, la tesis del autor. Primero, la fuerza histórica del lazo entre modernidad y mercado. Segundo, las controversias morales y políticas que este vínculo no cesa de suscitar desde hace siglos. Tercero, un alegato para que el lector reconozca que no se puede ser moderno si no se acepta el mercado. Para decirlo en breve, el Peña-sociólogo, el Peña-editorialista y el Peñaabogado se articulan orgánicamente en el libro. Veamos en detalle cada una de estas tesis.

Comencemos por el capítulo intermedio, aunque sólo sea porque sirve de soporte al título mismo del libro. Lo que el dinero sí puede comprar es en efecto también - pero no solamente y ni tan siquiera principalmente - una respuesta, polémica, al verdadero best seller mundial de Michael Sandel, Lo que el dinero no puede comprar. En el libro de Sandel, del cual Peña da una excelente presentación y una minuciosa lectura crítica, el tema central es la cuestión de los necesarios límites morales del mercado. Sandel ubica su reflexión en un momento histórico particular y desde una representación normativa específica; a saber, que las sociedades contemporáneas estarían sometidas a un proceso de mercantilización excesivo y desmedido. Aunque Sandel no emplee prácticamente, y curiosamente, el término de mercantilización, éste es el verdadero blanco de sus críticas. Peña trae a colación, con razón, el espectro de críticas clásicas en las que se inscribe el trabajo de Sandel, y se explaya al mostrar, con rigor lógico, un conjunto de contradicciones o falencias que constata en su obra. Volveremos en un momento 
sobre algunas de ellas, pero señalemos, desde ahora, que en su relectura crítica de ciertos temas álgidos actuales relacionados con el mercado y la sociedad Peña no se limita a la sola cuestión de la mercantilización. El capítulo 2 aborda también por lo menos otras dos grandes cuestiones: el tema de las desigualdades y el problema de la meritocracia.

¿Por qué comenzar esta reseña por el capítulo 2? Porque es probablemente la problemática que muchos lectores privilegiarán y las tesis con las cuales muchos estarán —o no- de acuerdo. La razón es simple: este capítulo exacerba la vocación propiamente polémica del libro. El Peña-editorialista, si puedo expresarme de esta manera, domina en este capítulo: los ejemplos y las discusiones, por rigurosas que sean $-\mathrm{y}$ lo son-, parecen al mismo tiempo indisociables de tomas de posición crítica hacia autores o agrupaciones políticas, nunca o muy rara vez explicitadas en el texto (sobre todo cuando se trata de autores o actores chilenos), pero que el lector puede a veces fácilmente entrever.

Levantemos el suspenso y entremos en el detalle de tres grandes interpretaciones críticas formuladas por el autor.

En primer lugar, la idea de la existencia de límites morales al mercado le parece a Peña un error de la parte de Sandel. Para el autor, el libro de Sandel no sólo aborda con cierto desorden temas que son muy distintos entre sí, sino que además lo hace a través de una lectura de índole moral que para Peña es un "retroceso" con respecto a interpretaciones de índole más estructural. Sin embargo, y habiendo reconocido lo anterior, no todo es desechable en el libro de Sandel (como parece finalmente sugerir Peña en su crítica apasionada). Muchos de los lectores del libro de Sandel recordarán, por ejemplo, una de las ilustraciones con las cuales se abre el texto: la proliferación, en los últimos años, de filas preferenciales para ciertos pasajeros en los trámites de aduana y de seguridad en los aeropuertos. A Sandel este "desborde" del mercado y este cuestionamiento de la igualdad le parecen injustificados, sobre todo cuando funcionarios son explícitamente destinados a garantizar un servicio diferencial, mediación económica mediante, a ciertos pasajeros. ¿Es legítimo que los pasajeros reciban un trato diferencial por parte de funcionarios públicos (agentes de aduana y policías) en función del precio de sus pasajes de avión? O, como sucede en ciertos aeropuertos, ¿que ciertos pasajeros puedan, siempre a través de una mediación económica, tener acceso a estas filas preferenciales? Para que cualquier 
lector lo entienda claramente, puesto que lo que está en cuestión es la ganancia de tiempo, ¿sería legítimo que en la circulación urbana algunas personas puedan pagar para tener acceso a vías rápidas y exclusivas con el fin de evitar los "tacos" en los cuales se verían enfrascados los otros automovilistas?

Por supuesto, se puede contraargumentar desde una lógica de mercado. A fin de cuentas, no se trataría sino de individuos-clientes que, en función de sus preferencias personales, deciden comprar un servicio porque valoran, más que otros individuos-clientes, su tiempo. Sobre este ejemplo en particular, Peña no se explaya en su libro y por ende sería un indebido proceso asociarlo a una u otra posición. Pero para Sandel, de manera explícita, este tipo de compras le parece moralmente indebido. Sin duda, que el término moral es equívoco, pero no por ello hay que desconocer lo que de justo anida en la tesis de Sandel; a saber, que en su despliegue el capitalismo es — también — una amenaza para la realización tanto de ciertos valores como de la igualdad. Sandel no critica el mercado sino sus excesos. Por supuesto, uno puede o no adherir a la lógica de la exposición de Sandel, y muchos considerarán que la idea de un "umbral" a partir del cual los beneficios del mercado se vuelven contra-productivos es una lectura ingenua o viciada. Pero ello no elimina ni la legitimidad de la pregunta ni la pertinencia de la inquietud del filósofo estadounidense; esto es, que el dinero puede conspirar contra ciertas modalidades de realización del individualismo a pesar de que, en la historia social de los dos últimos siglos, el vínculo entre ambos - mercado e individualismo - haya sido estrecho. Una tendencia histórica, sujeta por lo demás a controversia, no es una ley histórica.

En segundo lugar, Peña trae a colación el lazo fundamental entre el mercado y la meritocracia. La modernidad es, y no puede no ser, el triunfo del achievement sobre la adscription. O sea, la afirmación de las individualidades en la modernidad, vía el mercado, desemboca necesariamente en la entronización del mérito como gran principio de justicia. Peña sabe, esta vez como sociólogo, del carácter contundente de esta tesis y también sabe, esta vez como editorialista-polemista, de la irritación que este vínculo no cesa de suscitar en la sociedad chilena. Es contra esta "irritación", que le parece absolutamente injustificada, porque es histórica y lógicamente inconsistente, contra la cual polemiza. No hay, desliza Peña, esta vez a través de una afirmación indisocia- 
blemente factual y normativa, sociedad moderna sin meritocracia. Pero al concentrarse en el recordatorio de la fuerza estructural de este lazo, el libro evita ciertos debates tanto o más álgidos. ¿Puede en verdad el modelo de la selección, por el solo mérito de las élites, convertirse en el modelo pivote de la justicia? ¿La necesaria meritocracia a la cual está adosada la enseñanza superior no engendra acaso problemas específicos y estructurales (comenzando por la "soberbia de los inteligentes"), muy distintos a los que planteó la expansión de la educación primaria y secundaria que fueron verdaderos pivotes de la igualdad? ¿Qué sucede en el modelo implícito de la justicia como competencia — propia a la meritocracia - con los que "pierden", "fracasan" o "rechazan" la lógica de la carrera? ¿Cómo descuidar que estos actores constituyen, y no pueden no constituir, la mayoría de las personas? Sin regresar a las críticas, ampliamente conocidas, que la meritocracia enfrenta hace décadas (y que Peña conoce perfectamente), ¿qué parte del mérito diferencial de los individuos se debe a los colectivos de los cuales participan y forman parte? Peña tiene sin duda razón de recordar al lector el lazo estructural que la modernidad instituye entre el individualismo, el mérito y el mercado, y en este sentido el libro se propone "disolver" lo que para el autor no son sino falsas problemáticas, pero ello no debe obliterar los debates - altamente polémicos y legítimos - que acaecen en el universo de la justicia y que son irreductibles a la sola cuestión del mérito.

En tercer lugar, Peña trae a colación los lazos entre el mercado y la igualdad, recordándole al lector hasta qué punto, por ejemplo, la expansión del bienestar material ha sido dependiente de la eficiencia de los mercados, o, en un plano más político, hasta qué punto la expansión de la lógica del mercado conlleva una fuerza democratizadora en la sociedad. Una vez más, el libro circunscribe el debate en torno a lo que el autor considera son dimensiones decisivas de la modernidad, evitando discusiones que juzga abstrusas o simplemente mal informadas. Pero la articulación de estas realidades (progreso del bienestar, eficiencia económica, democracia) con el mercado, y éste con la igualdad, por estructural que se haya revelado en el seno de la modernidad, no por ello implica la existencia de vínculos infinitamente más complejos. Incluso, como una considerable literatura no cesa de señalarlo, la existencia de lazos reversibles, en la medida en que, por ejemplo, la penetración de la economía de mercado no conlleva, sino muy parcialmente, a la 
consolidación de la democracia en China; que se asiste a regresiones en el bienestar material a pesar de la eficiencia de los mercados; que la afirmación de la igualdad no es necesariamente concomitante con el incremento de la riqueza; y que incluso la expansión del mercado, tras la conquista, coincidió en una región como América Latina con la invención de la esclavitud. O sea, y el autor lo sabe bien, en las sociedades modernas el mercado se ha revelado como un factor necesario, pero no suficiente, para la expansión de la igualdad (o, para ser más precisos, para la expansión de una aspiración a la igualdad en lazo con el incremento del bienestar material). El Peña-sociólogo tiene razón en recordar los hechos, y en este sentido el libro tiene, aquí también, una pretensión casi terapéutica, la de eliminar del debate temáticas que le parecen al autor irrelevantes o falaces. Pero sobre esta base, el Peña-editorialista no se priva de su placer por la polémica al presentar la igualdad como la hija pródiga del mercado. Leyendo atentamente el libro, me parece que el lector puede incluso advertir hasta qué punto Peña se divirtió, mientras escribía, anticipando las reacciones que su libro suscitaría. Hay algo decididamente de enfant terrible en el autor.

\section{2.}

Habiendo establecido y reconocido lo anterior, ¿qué queda fuera de la mirada de Peña en este capítulo? Aunque no lo niegue, y sin duda no lo desestimaría, tal vez esto: las formas de realización personal que suponen reconocer, de manera distinta a como lo hace el mercado, el vínculo de los individuos entre sí y con los colectivos en el seno de la modernidad. Pero también, quizá, una atención más empática a la muy venerable tradición de la alienación; o, si se prefiere, del sinnúmero de patologías, efectos perversos o ambivalencias que suscita y no deja de suscitar el capitalismo. Al respecto, puede decirse de paso: tal vez no es un azar el que esta problemática, la del malestar frente a la modernización, haya sido introducida en Chile por Norbert Lechner, quien, dados sus orígenes alemanes, no podía sino ser particularmente sensible a esta tradición, puesto que si algo caracteriza a la intelectualidad alemana es justamente la oposición entre la razón instrumental y la cultura subjetiva. En su afán, por disipar lo que él entiende como formulaciones falaces, puesto que parten o dejan entrever la necesidad de tener que 
desembarazarse del mercado, Peña tiende por momentos a descalificar en exceso toda esta tradición crítica.

La pregunta es por qué. Aquí creo que el talante polemista - brillante - de Peña, el Peña-editorialista, se impone por sobre el análisis - profundo- que el Peña-sociólogo establece, como lo veremos en un momento, a propósito del vínculo entre el mercado, la modernidad y el individualismo. La fundamentación del lazo complejo entre estos términos y el justo reconocimiento de las inevitables consecuencias estructurales que esto conlleva cede el paso, no a una "defensa" del mercado, sino a la necesidad de tener que abandonar lo que para Peña no son sino formulaciones que tienden a denegar o evitar afrontar lo que el mercado le hace a la modernidad. Leyendo el libro, tal vez algún lector habrá pensado en esa anécdota de George Stephenson, uno de los inventores del tren a vapor, quien al ser preguntado sobre lo que pasaría si una vaca atravesara, en plena campiña, los rieles del tren, respondió de manera inmediata: tanto peor para la vaca. Hay algo de este talante modernizador en Peña: como Stephenson está convencido de la imperiosa necesidad de aceptar, sin tapujos ni mentiras, lo que el mercado impone en las sociedades modernas. Éste es el blanco principal de todas las críticas del autor. Peña detesta el moralismo, pero su libro, en su pasión polemista, tiene la fuerza de las mejores diatribas morales: develar la hipocresía, la mala fe o la falsa consciencia de todos aquellos que, usufructuando de los bienes del mercado y de los placeres del consumo, no cejan en el afán de denostarlo.

Pero al tomar esta perspectiva crítica, el libro adopta, sin justificarlo suficientemente, o sin hacerlo suficientemente transparente, una filosofía moral particular: el reconocimiento de la dimensión trágica de la existencia. Eso es, quizá, finalmente lo que realmente el dinero no puede comprar. La necesidad de reconocer, dentro de la modernidad, la imposibilidad del hombre para superar el mal — todo el mal- que es inherente a toda y cualquier estructura social. Por supuesto, es posible transformar las estructuras sociales para superar ciertos males (y es necesario conservar este objetivo si se cree en una cierta concepción de la política), pero ello no podrá nunca hacerse al precio de eludir enteramente el hecho de que la vida es trágica. Aunque Peña no señale este aspecto con la suficiente fuerza es, me parece, el corazón de su visión de la dinámica entre la vida individual y la vida colectiva. Aceptar las 
consecuencias inevitables del mercado (como de cualquier otra estructura social) forma parte, para Peña, de las sabidurías a las que la modernidad nos obliga. Es la falta de esta sabiduría existencial lo que, en el fondo, él denuncia en tantos críticos del mercado.

Tal vez, de haber reconocido con más transparencia esta posición, el autor habría podido advertir mejor una de las grandes especificidades de la sociedad estadounidense, que no es en absoluto ajena a su temática: a saber, que si Estados Unidos — en este punto sin duda más que Inglaterra, y muchísimo más que en otros países europeos, como Francia o Alemania - hizo del mercado el pivote del orden social es porque la cultura estadounidense carece, como pocas otras, de un sentimiento trágico de la existencia. En Estados Unidos, y casi sólo en este país, el dinero pudo y puede pretender ser una vía de acceso necesario $-\mathrm{y}$ a veces casi suficiente - a la felicidad. Peña no entreabre este debate a pesar de que, en el fondo, su visión crítica de los críticos del mercado se apoye, en mucho, sobre una sabiduría existencial particular. Si no lo hace es, tal vez, porque ello implicaría reconocer, mucho más de lo que el polemista está dispuesto a otorgar en algunos incisos rápidamente deslizados entre dos comas, que hay cosas que escapan al dinero.

3.

Si el capítulo 2 les permite a los lectores tomar posición, de manera esclarecida y controvertida, en debates mayores de las sociedades contemporáneas, ello no debe empero soslayar el hecho de que la tesis principal del libro se encuentra expuesta sobre todo en los capítulos 1 y 3 . A distancia esta vez de cuestiones coyunturales y polémicas, el Peña-sociólogo apuntala aquí con vigor el lazo entre la modernidad y el mercado. En breve: no hay modernidad sin mercado. Para sustentar esta afirmación, el autor presenta, a través de lecturas originales de muchos autores clásicos —-sociólogos, economistas, antropólogos-, algunas de ellas lejos de ser consensuales, la fuerza y la necesidad histórica del vínculo entre mercado y modernidad. En la literatura de las ciencias sociales latinoamericanas se trata sin duda de un aporte mayor. Si muchas de las cosas afirmadas en estos capítulos no son necesariamente desconocidas, no por ello fueron al menos temas voluntariamente descuidados. La modernidad fue y es un tema noble en las ciencias sociales 
en la región; el mercado fue y es un tema innoble. Los marxistas en América Latina, para no evocar sino a esta tradición, se guardaron bien de subrayar, por ejemplo, sin duda con mala fe, los elogios que Marx y Engels hicieron del rol del mercado (y el capitalismo) en el advenimiento del mundo moderno. El escaso reconocimiento del rol social y cultural de los comerciantes en la región sigue siendo una deuda pendiente en las ciencias sociales. Tras el libro de Peña, y esta vez gracias a la vocación polémica de la obra, será infinitamente más difícil obliterar estas dimensiones. Se hace necesario abocarse al estudio de la función efectiva que le corresponde al mercado en la historia del individualismo en América Latina.

Si el Peña-sociólogo toma la primacía en estos capítulos, los otros dos, el Peña-editorialista y sobre todo el Peña-abogado, no están empero muy lejos. El Peña-editorialista: con el fin de reforzar el carácter polémico de su tesis, el autor no duda en otorgarle una función dirimente - y por momentos unilateral - al mercado en el advenimiento de la modernidad. Sin duda, se podrá objetar que bajo esta modalidad la interpretación del mercado como matriz de la modernidad es excesiva, que otros factores importantes - en verdad consubstanciales a la modernidad - son minimizados, e incluso podría mostrarse que las lecturas propuestas de ciertas obras (por ejemplo, entre otras, la que se da a propósito de la función que el mercado tiene en la obra de Durkheim) deberían ser matizadas. Sobre todo, creo que sería necesario subrayar con mucha más fuerza de lo que lo hace el autor las múltiples ambivalencias - para decir lo menos - que la modernidad (iy el mercado!) han suscitado en muchos de los autores que evoca; y que sería necesario darles un acento mayor a otros factores que, independientemente del mercado, o en sinergia con él, han sido insumos indispensables de la modernidad: la Ilustración, la ciencia moderna, el modernismo, pero también la diferenciación social, la ciudad, la secularización; todo esto, sin olvidar la pluralidad de raíces del individualismo occidental desde hace siglos - tradición cristiana, el Renacimiento, los derechos del hombre y del ciudadano- y que no pueden ser directamente asociadas, o reducidas, a la lógica del mercado.

La modernidad no es el mercado, ni se reduce a él. La modernidad es la aceptación de la ruptura de la totalidad, del lazo "orgánico" entre lo objetivo y lo subjetivo, entre la historia y la biografía; la necesidad 
de afrontar una vida sin script (o sea, sin destino) y, por ende, una vida sometida a un incesante trabajo de evaluación y de conciencia. En el advenimiento histórico de la sociedad moderna, el mercado ha tenido sin duda una función dirimente (y contra todos los filisteos anti-mercado, Peña tiene razón en muchas de sus críticas). Pero la modernidad no es reductible al mercado. En el corazón de la modernidad se encuentra una tensión especifica entre la economía y la subjetividad, algo que Peña no solamente conoce, sino que explícitamente reconoce en su libro y que, al mismo tiempo, empero, tiende a desestimar. Es tal vez el precio necesario a pagar por una adhesión sin timideces al talante modernizador, el "tanto peor para las vacas".

Sin embargo, en honor a la verdad, creo que todos estos necesarios matices introducidos no alteran en el fondo la fuerza de la tesis central del libro: la ruptura de la totalidad de la cual nace y se nutre la modernidad tiene históricamente, de una u otra manera, tarde o temprano, vínculos con el mercado. Ésta es la gran proposición del libro y es, por supuesto, un escándalo en el contexto de las ciencias sociales latinoamericanas. Para defender este escándalo — iy con qué placer! — aparece el Peña-abogado. El libro subrepticiamente toma un cariz particular. Es falso, sin duda, decir que la dimensión factual cede a una dimensión normativa, pero es justo, creo, reconocer que, una vez mostrada la plausibilidad de la tesis de la necesidad de este vínculo, se pasa a un alegato que insiste en la necesidad de tener que enfrentar — sin escapatoria posible - las consecuencias de lo que el mercado le hace a la modernidad. El resto, aunque Peña no lo escriba pero lo piensa, es pura mala fe sartriana; una manera, durante mucho tiempo muy frecuente en las sociedades latinoamericanas, de mentirse a ellas mismas.

La vocación polémica del libro encuentra aquí su plena razón de ser. Peña lo dice de muchas maneras en su libro, pero es esta tesis y sus consecuencias lo que le parece debe ser hoy prioritariamente discutido en las ciencias sociales y, sin duda, en el espacio público en Chile. En este plano y con vistas a este objetivo, la libertad de tono del libro es encomiable. Es lo que hace de él un libro importante en las ciencias sociales de la región. Pocas veces, y con tanta contundencia, se ha propuesto una relectura informada y crítica, desde América Latina, de la función dirimente e irrevocable del mercado en la modernidad. En este sentido, y dados los desafíos a los cuales se enfrentan hoy las socieda- 
des latinoamericanas, cada una desde coordenadas nacionales disímiles, no es exagerado decir que este libro tenía que ser escrito. Y tal vez, escrito como lo ha sido: articulando pasiones y razones; descartando y disipando "falsos" debates con el fin de imponer "necesarias" discusiones; expresando un gran placer en irritar a muchos y escandalizar a tantos otros; aunando, con talento, las voces del sociólogo, del editorialista y del abogado.

Peña tiene razón en lo que impone como horizonte central en la discusión. Ahora cada cual deberá darle una respuesta: qué se hace con lo que el mercado le hace a la modernidad. EP 
